\title{
Bacteriological Profile and their Antibiogram in Post Cesarean Patients with Surgical Site Infections
}

\author{
Priyanka Soni $^{1 *}$, Kiran Griwan ${ }^{1}$, Aditya Griwan ${ }^{2}$, Manoj Soni $^{3}$, \\ Savita Singhal ${ }^{4}$ and Aparna Yadav ${ }^{1}$ \\ ${ }^{1}$ Department of Microbiology (PGIMS) Rohtak, Haryana, India \\ ${ }^{2}$ PGIMS Rohtak, Haryana, India \\ ${ }^{3}$ HCMS, Haryana, India \\ ${ }^{4}$ Department of Obstetrics and Gynaecology (PGIMS) Rohtak, Haryana, India \\ *Corresponding author
}

\section{A B S T R A C T}

\section{Ke y w o r d s \\ Surgical Site infections, Multidrug resistance, MRSA, Post-operative wound, Nosocomial infection}

\section{Article Info}

Accepted: 15 April 2020 Available Online: 10 May 2020
Surgical site infection(SSI) is among the most common causes of nosocomial infections in the literature. SSI increases the financial burden, length of hospital stays and significant morbidity and mortality of the patient. These infections have a tremendous impact on morbidity and mortality as SSIs doubled the patient's risk of death after surgery Therefore despite all recent advances, SSI still continue to be a major problem in the hospitals even with all available modern facilities. To study bacteriological profile and their antibiogram in post cesarean patients with surgical site infections. A prospective study was conducted in the Departments of Microbiology and Obstetrics \& Gynaecology, Pt. B.D. Sharma Post Graduate Institute of Medical Sciences, Rohtak over a period of one year. A total of 150 patients with post cesarean surgical wound infection were enrolled for the study. The pus discharge from SSI was collected post operatively from patients and was processed as per standard microbiological procedure. The evaluation of bacteriological profile of samples from 150 patients revealed that majority of the cultures were sterile i.e. 127 (84.6\%) and bacterial growth was seen in $23(15.33 \%)$ patients in the study population. Out of 23 isolates, 16 had monomicrobialetiology while remaining 7 had polymicrobialetiology. Result we obtained from the study is comparable to other studies in literature. Strict infection control measures like maintenance of proper hand hygiene and optimal preoperative, intraoperative and postoperative patient care will surely reduce the incidence of SSIs.

\section{Introduction}

A surgical site infection (SSI) is defined as an infection which occurs at the incision / operative site (including drains) within 30 days after surgical operation. This definition includes clinical signs and symptoms of infection rather than microbiological evidence alone as skin is normally colonized by microorganisms that can cause infection. ${ }^{1}$ SSI is among the most common causes of nosocomial infections with a reported incidence rates of $2-20 \%$ in the literature. ${ }^{2}$ These infections are usually caused either by 
exogenous or endogenous microorganisms that enter the surgical wound either during the surgery (primary infection) or after the surgery (secondary infection). ${ }^{3}$ Emergency procedures, wound class, wound contamination, extremes of age, metabolic disease, immunosuppressant, malnutrition, remote site infection, duration of preoperative and post-operative hospital stay, preexisting illness and length of surgical operation are some important factors which influence the incidence of surgical site infections. $^{4,5,6}$ SSI increases the financial burden, length of hospital stay and significant morbidity and mortality of the patient. Therefore despite all recent advances, SSI still continue to be a major problem in the hospitals even with all available modern facilities.

Cesarean section carries 5 to 20 fold increased risk of infection compared to vaginal delivery. Depending upon the surveillance methods used to identify infections, the patient population, and the use of preoperative antibiotic prophylaxis, the rate of SSI after cesarean section is found to be in the range of $3 \%$ to $15 \%$. Unnecessary cesarean sections should be avoided as they are also associated with an additional potential risk of iatrogenic prematurity. The most common postoperative infections following caesarean section are urinary tract infections, surgical site infection (SSI) or infections of the pelvic organs. ${ }^{7,8}$

The problem of SSI continues to be a problem even after maintaining the standard protocol of pre-operative preparations and antibiotic prophylaxis. Multi and single centered studies showed that the majority of organisms causing SSI are gram positive cocci e.g. $S$. aureus and gram negative bacilli e.g. E. coli, Klebsiella, Pseudomonas and Enterobacter spp. ${ }^{9,10}$ However, the most significant change in the microbiology of SSI has been the increased involvement of resistant organisms like MRSA. ${ }^{11}$ Therefore, this study was designed to determine current spectrum of organism in SSI and their antibiotic susceptibility in post cesarean patients so that results could be helpful for treating obstetricians in postoperative care and management.

\section{Materials and Methods}

A prospective study was conducted in the Departments of Microbiology and Obstetrics \& Gynaecology, Pt. B.D. Sharma Post Graduate Institute of Medical Sciences, Rohtak over a period of one year. A total of 150 patients with post cesarean surgical wound infection were enrolled for the study. The sample was collected from the patient with post cesarean surgical wound pus discharge, with signs of infection like erythema, induration, tenderness, pain, raised local temperature were included. Patients with Chorioamnionitis, peritonitis and fever prior to cesarean section are excluded from the study. The pus sample from the wound was collected with the help of two sterile swab sticks from the patient under all aseptic conditions and was transported in brain heart infusion (BHI) broth to microbiology laboratory as early as possible.

Out of the two swabs one swab was used for gram staining for early presumptive diagnosis. Second swab was inoculated on blood agar and MacConkey agar plates and plates were incubated at $37^{\circ} \mathrm{C}$ for $24-48$ hours, followed by processing and identification on the basis of colony morphology, staining characteristics and biochemical reactions as per standard microbiological procedure. ${ }^{12-14}$ All the isolates were tested for antimicrobial susceptibility testing by Kirby-Bauer disc diffusion method on Muller-Hinton agar and results were interpreted in accordance with Clinical and Laboratory Standards Institute (CLSI) 2017 
guidelines. ${ }^{15}$ Antimicrobial discs were procured from HiMedia Laboratories, Mumbai, India. Direct colony suspension of control strain of Staphylococcus aureus ATCC 25923, Escherichia coli ATCC 25922 and Pseudomonas aeruginosa ATCC 27853 was also prepared and standardized as above.

\section{Results and Discussion}

The age of patients in our study ranged from $15-45$ years with mean age of $25.10 \pm 3.99$. It was found that maximum numbers of patients i.e. $67(44.6 \%)$ belong to age group 21-25 years followed by $26-30$ years i.e. 53 (35.33\%). Among 150 patients, 147 (98\%) underwent emergency cesarean section while only 3 underwent elective procedure. The evaluation of bacteriological profile of samples revealed that majority of the cultures were sterile i.e. $127(84.6 \%)$ and bacterial growth was seen in $23(15.33 \%)$ patients in the study population as shown in table 1 .

Out of 23 isolates, 16 had monomicrobialetiology while remaining 7 had polymicrobialetiology. Among monomicrobial isolates, majority (9 out of 16) were gram negative organisms and remaining 7 were gram positive organisms. Among monomicrobial isolates, Staphylococcus spp. was the most common isolate (43.75\%) followed by Escherichia coli (25\%) and Pseudomonas spp. (12.5\%), while Acinetobacter spp, Enterobacter spp. and Klebsiellaspp. (6.25\%) isolates were in equal proportion as shown in table 2 .

In polymicrobial isolates, $13(92.85 \%)$ were gram negative while only 1 was gram positive organism. Among polymicrobial isolates, Acinetobacter spp.+ Escherichia coli was the most common isolate $(28.57 \%)$ as shown in table 3. Antibiotic profile of gram negative bacteria other than Pseudomonas spp. and Acinetobacter baumanniiin post cesarean patients with SSI shown in table 4. Both the strains of Pseudomonas spp. were found sensitive to amikacin, ciprofloxacin, imipenam, and meropenam while resistant to ceftazidime, gentamycin and cefepime.

All the strains of staphylococcus spp. were found sensitive to linezolid and doxycycline while variable susceptibility pattern was seen for other antimicrobial agents as shown in table 5. Antimicrobial susceptibility and resistance pattern of organisms in polymicrobial infection shown in table 6 . Majority of organisms were found sensitive to imipenam, meropenam and resistant to cefepime, ceftazidime. Table 7 shows that 25 out of 30 organisms $(83.33 \%)$ were found multi-drug resistant and no organism was found sensitive or resistant to all drugs. Table 8 shows that $62.5 \%$ of staphylococcus spp. was Methicillin resistant.

Surgical site infections (SSIs) are the most common post-operative complications in patients who undergo abdominal surgerieswhether emergency or elective. Caesarean section carries 5to 20-fold increased risk of infection compared to vaginal delivery. Depending upon the surveillance methods used to identify infections, the patient population, and the use of preoperative antibiotic prophylaxis, the rate of SSI after cesarean section is found to be in the range of $3 \%$ to $15 \%$. Such SSIs show variable presentations, etiology and severity that involve microbial invasion of the layers of the skin and soft tissues. The most important challenge of SSIs is to efficiently differentiate those cases that require immediate attention and intervention, whether medical or surgical, from those that are less severe. ${ }^{16}$ Unfortunately, in the majority of cases undergoing surgery and who go on to develop SSIs, the precise nature of bacterial etiology remains unknown and the clinicians are forced to prescribe the antibiotics empirically 
aided by individual experiences. Given the observation that antimicrobial resistance among various isolates shows wide variations, it becomes very difficult to select the specific antibiotics for management of such patients. Keeping in view that SSI is major postoperative complication in surgical patients in hospital settings, therefore this study was conducted to determine current spectrum of organism in SSI and their antibiotic susceptibility in post cesarean patients so that results could be helpful for treating obstetricians in empirical selection of right kind of antibiotics, postoperative patient care and management. ${ }^{17,18}$

In the present study, age of patients ranged from 15 to 45 years with mean age as 25.10 years. The majority of patients were in 21-25 years of age (44.6\%) followed by 26-30 years $(35.33 \%)$. It shows most of affected patients were young individuals.

In the present study, we came across more number of emergency cesarean sections as compared to planned elective surgeriesAmong 150 patients, 147 (98\%) underwent emergency caesarean section while only 3 underwent elective procedure. In the present study, SSI rate of $15.33 \%$ was obtained which compares favorably with other reported rates ranging from 2.5 to $41.9 \% .{ }^{19-23}$ Various other studies from India have shown that the rate of SSI varies from $6.1 \%$ to $38.7 \%$. However the rate of infection reported from other countries is quite low, 2.8\% in USA and in European countries it is reported to be $2-5 \%$ as compared to India. ${ }^{24}$

In the present study, $22(73.33 \%)$ out of 30 organisms (including both monomicrobial and polymicrobial infection) were gram negative and remaining $8(26.66 \%)$ were gram positive. Among gram negative organisms, the most common organism isolated was Escherichia coli $23.33 \%$ followed by Acinetobacter spp. 16.6\%, Pseudomonas spp.
13.33\%, Enterobacter spp $10 \%$, Klebsiella spp. $6.66 \%$ and Citrobacter spp. $3.33 \%$. Among gram positive organisms only staphylococcus spp. was isolated. Among the gram positive organisms, Staphylococcus aureus was the most common isolate (16.4\%) followed by coagulase negative Staphylococcus $(4.68 \%)$ and Enterococcus spp. (3.12\%).

Literature shows the importance of antimicrobial prophylaxis which is refers to a brief course of an antimicrobial agent which is initiated prior to surgery so as to prevent SSI. Antibiotic prophylaxis in surgical patients has always been a matter of debate. For prophylactic antibiotic the current recommendation states that the parenteral antibiotic must be given within 2 hours of incision so as to attain high tissue and serum levels during surgery. However, at many institutes prophylactic antibiotics have been withheld until after the umbilical cord has been clamped. History of prior exposure to hospital facilities, irrational use of broad spectrum antibiotics and any invasive surgical procedure is an important breeding ground which further aid in development of resistance to common antimicrobials and has deteriorated this condition of SSI. ${ }^{1}$ Antibiotic susceptibility results revealed among gram positive and gram negative organism.

\section{Gram negative organisms}

E. coli: seven strains isolated showed varying degree of susceptibility to antimicrobials tested. Majority of the strains were uniformly susceptible to imipenam and meropenam $(85.7 \%)$..

Acinetobacter spp.: All the five strains were uniformly susceptible to imipenam and meropenam (100\%) followed by doxycycline $(80 \%)$, ciprofloxacin (60\%), and amikacin $(50 \%)$. 
Pseudomonas spp.: All the four strains were uniformly susceptible to amikacin, ciprofloxacin, imipenam and meropenam $(100 \%)$

Enterobacter spp.: All the three strains were uniformly susceptible to ciprofloxacin, imipenam and meropenam (100\%) while less susceptibility was seen to gentamycin, amikacin, piperacillin-tazobactam, cotrimoxazole $(66.6 \%)$.

Klebsiella spp.: Both the strains were uniformly susceptible to gentamycin, imipenam and meropenam (100\%) while less susceptibility was seen to ampicillin, amikacin, amoxicillin-clavunate, piperacillintazobactam, cefuroxime, cefoxitin and cotrimoxazole (50\%).

Citrobacterfreundii: The single isolate was sensitive to amikacin, imipenam and meropenam.

\section{Gram positive organisms}

\section{Staphylococcus spp}

All the eight strains were uniformly susceptible to linezolid and doxycycline $(100 \%)$. Less susceptibility was seen to clindamycin and co-trimoxazole (75\%), erythromycin (62.5\%), cefoxitin $(37.5 \%)$ and least to penicillin (12.25). In our study 25 out of thirty isolates showed multidrug resistance. Among the 8 isolates of staphylococcus species $5(62.5 \%)$ were found to be methicillin resistant. Present study had few limitations viz. in majority of cases, patient had antibiotics administered by clinicians before beginning the surgery. Patients may have also carried along some community acquired microorganisms or from their own flora and also from operation theatre environment including surgeons or staff. Although clear cut protocol for specimen collection for cases of SSIs was there in the present study, but nonetheless, the nature of isolates and antibiotics sensitivity pattern may have undergone a change or else resistance acquisition mechanisms may have evolved in hospital environment and it is well known that hospital strains are more resistant. During the course of the study it was realized that the proper collection of clinical specimen and timely processing in laboratory is an important factor for isolation of apparently causative organisms.

Furthermore it is realized and experienced that the isolation of potentially pathogenic bacteria coupled with attempts to assess the status of susceptibility to 'in use' antibiotics in our hospital is extremely very important. It is highly significant for the reasons that it will go a long way in reducing morbidity and mortality in our esteemed institution. It is strongly felt that the study undertaken has met with success and results obtained with suggestions formulated will contribute to strengthening patient care services in our tertiary care city hospitals.

Table.1 Bacteriological profile of samples in the study population

\begin{tabular}{|l|c|c|}
\hline Culture & No. of patients $(\mathbf{n = 1 5 0})$ & Percentage (\%) \\
\hline Bacterial growth & 23 & $15.33 \%$ \\
\hline Sterile culture & 127 & $84.6 \%$ \\
\hline
\end{tabular}


Table.2 Distribution of monomicrobial organisms isolates

\begin{tabular}{|l|c|}
\hline Organisms & No. of findings $(\mathbf{n = 1 6})$ \\
\hline Staphylococcus spp. & 7 \\
\hline Escherichia coli & 4 \\
\hline Pseudomonas spp. & 2 \\
\hline Acinetobacter spp. & 1 \\
\hline Enterobacter spp. & 1 \\
\hline Klebsiellaspp. & 1 \\
\hline
\end{tabular}

Table.3 Distribution of polymicrobial organisms isolated

\begin{tabular}{|l|c|}
\hline Organisms & No. of findings \\
\hline $\begin{array}{l}\text { Acinetobacter spp.+ } \\
\text { Escherichia coli }\end{array}$ & 2 \\
\hline $\begin{array}{l}\text { Escherichia coli }+ \\
\text { Pseudomonas } \text { spp. }\end{array}$ & 1 \\
\hline $\begin{array}{l}\text { Staphylococcus aureus }+ \\
\text { Citrobacterspp. }\end{array}$ & 1 \\
\hline $\begin{array}{l}\text { Klebsiella } \text { spp. }+ \\
\text { Acinetobacter } \text { spp. }\end{array}$ & 1 \\
\hline $\begin{array}{l}\text { Pseudomonas } \text { spp. }+ \\
\text { Enterobacter } \text { spp. }\end{array}$ & 1 \\
\hline $\begin{array}{l}\text { Enterobacter } \text { spp. }+ \\
\text { Acinetobacter } \text { spp. }\end{array}$ & 1 \\
\hline
\end{tabular}

Table.4 Antibiotic susceptibility pattern of gram negative isolates except Pseudomonas spp. and Acinetobacter baumanniiin post cesarean patients among monomicrobial isolates

\begin{tabular}{|l|c|c|c|}
\hline $\begin{array}{l}\text { Antimicrobial } \\
\text { agents }\end{array}$ & $\begin{array}{c}E . \text { coli } \\
(\mathbf{n = 4})\end{array}$ & $\begin{array}{c}\text { K. oxytoca } \\
(\mathbf{n = 1})\end{array}$ & $\begin{array}{c}\text { Enterobacter } \\
\text { aerogenes }(\mathbf{n}=\mathbf{1})\end{array}$ \\
\hline AMP & 2 & 0 & 0 \\
\hline G & 3 & 1 & 1 \\
\hline AK & 3 & 1 & 1 \\
\hline AMC & 3 & 0 & 0 \\
\hline PTZ & 3 & 0 & 1 \\
\hline CXM & 1 & 0 & 0 \\
\hline CPM & 1 & 0 & 1 \\
\hline CX & 1 & 0 & 1 \\
\hline CTX & 1 & 0 & 1 \\
\hline CIP & 2 & 0 & 1 \\
\hline IMP & 4 & 1 & 1 \\
\hline MRP & 4 & 1 & 1 \\
\hline COT & 2 & 1 & 0 \\
\hline AT & 2 & 0 & \\
\hline
\end{tabular}

$\mathrm{AMP}=$ Ampicillin, $\mathrm{G}=$ Gentamycin, $\mathrm{AK}=$ Amikacin, $\mathrm{AMC}=$ Amoxicillin-clavunate, $\mathrm{PTZ}=$ Piperacillintazobactam, $\mathrm{CXM}=$ Cefuroxime, $\mathrm{CPM}=$ Cefepime, $\mathrm{CX}=$ Cefoxitin, $\mathrm{CTX}=$ Cefotaxime, $\mathrm{CIP}=$ Ciprofloxacin, $\mathrm{IMP}=$ Imipenam, $\mathrm{MRP}=$ Meropenam, $\mathrm{COT}=\mathrm{Co}$-trimoxazole, $\mathrm{AT}=\mathrm{Aztreonam}$ 
Table.5 Antibiotic susceptibility pattern of S. aureus and CONS (coagulase negative staphylococcus species) in post cesarean patients

\begin{tabular}{|l|c|c|}
\hline $\begin{array}{l}\text { Antimicrobial } \\
\text { agents }\end{array}$ & $\begin{array}{c}\text { S. aureus } \\
(\mathbf{n}=\mathbf{6})\end{array}$ & $\begin{array}{c}\text { CONS } \\
(\mathbf{n}=\mathbf{1})\end{array}$ \\
\hline E & 4 & 0 \\
\hline CD & 4 & 1 \\
\hline CX & 2 & 1 \\
\hline P & 1 & 0 \\
\hline COT & 5 & 0 \\
\hline LZ & 6 & 1 \\
\hline DO & 6 & 1 \\
\hline
\end{tabular}

$\mathrm{E}=$ Erythromycin, $\mathrm{CD}=$ Clindamycin, $\mathrm{CX}=$ Cefoxitin, $\mathrm{P}=$ Penicillin, $\mathrm{COT}=$ Co-trimoxazole, $\mathrm{LZ}=$ Linezolid, DO= Doxycycline

Table.6 Antibiotic susceptibility pattern in organisms of polymicrobial infection in post cesarean patients

\begin{tabular}{|c|c|c|c|c|c|c|c|c|c|c|c|c|}
\hline \multirow[t]{2}{*}{$\begin{array}{l}\text { Antimicrobial } \\
\text { agents }\end{array}$} & \multicolumn{2}{|c|}{$\begin{array}{c}\text { E. coli } \\
+ \\
\text { A. spp. } \\
(\mathbf{n}=2)\end{array}$} & \multicolumn{2}{|c|}{$\begin{array}{c}\text { A. } \quad \begin{array}{c}\text { baumannii } \\
+ \\
\text { Ent. aerogenes } \\
(\mathrm{n}=1)\end{array} \\
\end{array}$} & \multicolumn{2}{|c|}{$\begin{array}{c}\text { Ps. spp. } \\
+ \\
\text { Ent. spp. } \\
(\mathrm{n}=1)\end{array}$} & \multicolumn{2}{|c|}{$\begin{array}{c}\text { K. pneumonia } \\
+ \\
\text { A. } \\
\\
\\
(\mathrm{n}=1)\end{array}$} & \multicolumn{2}{|c|}{$\begin{array}{l}\text { S. aureus } \\
+ \\
\begin{array}{l}\text { C. freundii } \\
(\mathrm{n}=1)\end{array}\end{array}$} & \multicolumn{2}{|c|}{$\begin{array}{c}\text { E. coli } \\
+ \\
\text { Ps. } \\
\text { aeruginosa } \\
(\mathrm{n}=1)\end{array}$} \\
\hline & a & $\mathrm{b}$ & $\mathrm{a}$ & $\mathrm{b}$ & $\mathrm{a}$ & $\mathrm{b}$ & a & b & $\mathrm{a}$ & b & A & B \\
\hline AMP & 0 & - & - & 0 & - & 0 & 1 & - & - & 0 & 0 & - \\
\hline G & 1 & 0 & 1 & 1 & 0 & 0 & 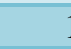 & 0 & - & 0 & 1 & 1 \\
\hline AK & 1 & 1 & 1 & 1 & 1 & 0 & 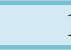 & 0 & - & 1 & 1 & 1 \\
\hline AMC & 0 & - & - & 0 & - & 0 & ( & - & - & 0 & 1 & - \\
\hline PTZ & 1 & 0 & 0 & 1 & 0 & 0 & 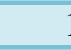 & 0 & - & 0 & 1 & 1 \\
\hline CXM & 1 & - & - & 0 & - & 0 & 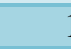 & - & - & 0 & 0 & - \\
\hline CPM & 0 & 0 & 0 & 0 & 0 & 0 & ( & 0 & - & 0 & 0 & 0 \\
\hline CX & 1 & - & - & 0 & - & 0 & 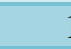 & - & 0 & 0 & 0 & - \\
\hline CTX & 1 & 0 & 0 & 0 & - & 0 & ( & 0 & - & 0 & 0 & - \\
\hline CIP & 0 & 1 & 1 & 1 & 1 & 1 & ( & 0 & - & 0 & 1 & 1 \\
\hline IMP & 1 & 2 & 1 & 1 & 1 & 1 & 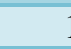 & 1 & - & 1 & 1 & 1 \\
\hline MRP & 1 & 2 & 1 & 1 & 1 & 1 & 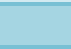 & 1 & - & 1 & 1 & 1 \\
\hline COT & 2 & - & - & 1 & - & 0 & 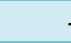 & - & 1 & 0 & 1 & - \\
\hline AT & 0 & - & - & 0 & 0 & 0 & . & - & - & 0 & 0 & 0 \\
\hline CAZ & - & 0 & 0 & - & 0 & - & ( & 0 & - & - & - & 0 \\
\hline $\mathbf{E}$ & - & - & - & - & - & - & 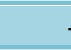 & - & 1 & - & - & - \\
\hline CD & - & - & - & - & - & - & 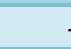 & - & 1 & - & - & - \\
\hline $\mathbf{P}$ & - & - & - & - & - & - & 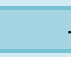 & - & 0 & - & - & - \\
\hline $\mathbf{L Z}$ & - & - & - & - & - & - & 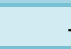 & - & 1 & - & - & - \\
\hline DO & - & 2 & 1 & - & - & - & . & - & 1 & - & - & - \\
\hline
\end{tabular}

$\mathrm{AMP}=$ Ampicillin, $\mathrm{G}=$ Gentamycin, $\mathrm{AK}=$ Amikacin, $\mathrm{AMC}=$ Amoxicillin-clavunate, $\mathrm{PTZ}=$ Piperacillin-tazobactam, $\mathrm{CXM}=$ Cefuroxime, $\mathrm{CPM}=$ Cefepime, $\mathrm{CX}=$ Cefoxitin, $\mathrm{CTX}=$ Cefotaxime, $\mathrm{CIP}=$ Ciprofloxacin, IMP= Imipenam, $\mathrm{MRP}=$ Meropenam, $\mathrm{COT}=\mathrm{Co}$-trimoxazole, $\mathrm{AT}=\mathrm{Aztreonam}, \mathrm{CAZ}=$ Ceftazidime, $\mathrm{E}=$ Erythromycin, $\mathrm{CD}=$ Clindamycin, $\mathrm{CX}=$ Cefoxitin, $\mathrm{P}=$ Penicillin, $\mathrm{LZ}=$ Linezolid, $\mathrm{DO}=$ Doxycycline 
Table.7 Prevalence of drug resistance in bacteria isolated from patients of SSI

\begin{tabular}{|l|c|c|c|c|}
\hline Bacterial isolate & No. of isolates & $\begin{array}{c}\text { Resistant to all } \\
\text { drugs }\end{array}$ & $\begin{array}{c}\text { Resistant to } \geq \mathbf{3} \\
\text { drugs }\end{array}$ & $\begin{array}{c}\text { Sensitive to all } \\
\text { drugs }\end{array}$ \\
\hline Staph. spp. & 8 & 0 & 4 & 0 \\
\hline E. coli & 7 & 0 & 6 & 0 \\
\hline Ac. spp. & 5 & 0 & 5 & 0 \\
\hline Ps. spp. & 4 & 0 & 4 & 0 \\
\hline Ent. spp. & 3 & 0 & 3 & 0 \\
\hline Kleb. spp. & 2 & 0 & 2 & 0 \\
\hline Citro. Spp. & 1 & 0 & 1 & 0 \\
\hline Total & $\mathbf{3 0}$ & $\mathbf{0}$ & $\mathbf{2 5}$ & $\mathbf{0}$ \\
\hline
\end{tabular}

Table.8 Prevalence of Methicillin resistant staphylococcus species in patients of SSI

\begin{tabular}{|l|c|c|}
\hline No. of isolate & Sensitive to methicilin & Resistant to methicilin \\
\hline 8 & 3 & 5 \\
\hline
\end{tabular}

The evaluation of bacteriological profile of samples revealed that majority of the cultures were sterile i.e. $127(84.6 \%)$ and bacterial growth was seen in $23(15.33 \%)$ patients in the study population. So we obtained SSI rate of $15.33 \%$ in this study which is comparable to other studies in literature. Out of 23 isolates, 16 had monomicrobialetiology while remaining 7 had polymicrobialetiology. Methicillin resistance was seen in $62.5 \%$ of staphylococcus spp. Out of 30 organisms, 25 $(83.33 \%)$ were found multi-drug resistant and no organism was found sensitive or resistant to all drugs. Determining the spectrum of organism in SSI and proper selection of antibiotic therapy is a critical adjunctive to the overall treatment plan. It must be guided by laboratory antimicrobial sensitivity pattern studies in all but individual cases.

\section{References}

1. Bruce J, Russel EM, Mollison J. The measurement and monitoring of surgical adverse events. Health Technol Assess.2001;5:13-28.

2. Hohmann C, Eickhoff C, Radziwill R, Schulz M. Adherence to guidelines for antibiotic prophylaxis in surgery patients in German hospitals: a multicentre evaluation involving pharmacy interns. Infection. 2012;40(2):131-137.

3. Owens CD, Stoessel K. Surgical site infections: epidemiology, microbiology and prevention. Journal of Hospital Infection.2008;70:3-10.

4. Nandi PL, Rajan SS, Mak KC, Chan SC. Surgical wound infection. Hong Kong Med J. 1999;5:826.

5. Saxena A, Singh M, Brahmchari S, Banerjee M. Surgical site infection among post-operative patients of tertiary care centre in central India - A prospective study. AJBPR. 2013;17:41-4.

6. Imai E, Ueda M, Kanao K, Kubota T, Hasegawa H, Omae K, Kitajima M. Surgical site infection risk factors identified by multivariate analysis for patients undergoing laparoscopic, open colon and gastric surgery. Am J Infect Control. 2008;10:727-31.

7. Smaill, FM., Gyte, GML. Antibiotic prophylaxis versus no prophylaxis for preventing infection after caesarean section. Cochrane Database Syst Rev. 2010;20(1):CD007482. 
8. Smaill, F., Hofmeyr, GJ. Antibiotic prophylaxis for cesarean section. Cochrane Database Syst Rev. 2002;(3):CD000933.

9. Anderson DJ, Sexton DJ, Kanafani ZA, Auten G, Kaye KS. Severe surgical site infection in community hospitals: epidemiology, key procedures and the changing prevalence of methicilinresistant Staphylococcus aureus. Infect Control HospEpidemiol. 2007; 28:104753.

10. CantlonCA, Stemper ME, Schwan WR, Hoffman MA, Qutaishat SS. Significant pathogens isolated from surgical site infections at a community hospital in the Midwest. Am J Infect Control. 2006;34:526-29.

11.Jernigan JA. Is the burden of Staphylococcus aureus among patients with surgical-site infection growing? Infect Control HospEpidemiol. 2004;25:457-60.

12. Forbes BA, Sahm DF, Weissfeld AS. Traditional cultivation and identification. Bailey and Scott's Diagnostic Microbiology.12th ed. Misssouri: Mosby ;2007.p.93-119.

13. Duguid JP. Staining methods. In: Collee JG, Marmion BP, Fraser A. Mackie \& McCartney, Practical Medical Microbiology. 14th ed. London: Churchill Livingstone; 2016.p.793-812.

14. Winn WJ, AllenS, Janda W, Koneman E, ProcopG,Woods Gail, et al., Koneman's color atlas \& textbook of diagnostic microbiology. 6thed .USA .Wolter Kluwer;2005.

15.CLSI, Performance standards for antimicrobial susceptibility testing, 27th ed. CLSI document MI00-S27. Wayne, Pennsylvania: Clinical and Laboratory Standards Institute, 2017.

16. Ki V, Rotstein C. Bacterial skin and soft tissue infections in adults: A review of their epidemiology, pathogenesis, diagnosis, treatment and site of care. Can J Infect Dis Med Microbiol. 2008; 19(2):173-84.

17. Swartz MN. Clinical practice. Cellulitis. N Engl J Med. 2004;350:904-12.

18. Eron LJ, Lipsky BA, Low DE, Nathwani $\mathrm{D}$, Tice AD, Volturo GA. Managing skin and soft tissue infections: Expert panel recommendations on key decision points. $\mathbf{J}$ AntimicrobChemother. 2003;52:3-17.

19. Anvikar AR, Deshmukh AB, Damle AS et al., A one year prospective study of 3280 surgical wounds. Ind J Med Microbiol. 1999;17:129-32.

20. Agarwal SL. Study of postoperative infections. Ind J Surg. 1972;34:314-20.

21. Rao AS, Harsha M. Postoperative wound infections. $J$ Ind Med Assoc. 1975;64(4):90-93.

22. Tripathy BS, Roy N. Post-operative wound sepsis. Ind J Surg. 1984;47:28588.

23. Kowli SS, Nayak MH, Mehta AP, Bhalerao RA. Hospital Infection. Indian J Surg. 1985;48:475-86.

24. Khan A, Rashed M, Banu G. A Study on the usage pattern of antimicrobial agents for the prevention of surgical site infection (SSI) in a tertiary care teaching hospital. J ClinDiagn Res. 2013;7(4):671-74.

\section{How to cite this article:}

Priyanka Soni, Kiran Griwan, Aditya Griwan, Manoj Soni, Savita Singhal and Aparna Yadav. 2020. Bacteriological Profile and their Antibiogram in Post Cesarean Patients with Surgical Site Infections. Int.J.Curr.Microbiol.App.Sci. 9(05): 1592-1600. doi: https://doi.org/10.20546/ijcmas.2020.905.180 